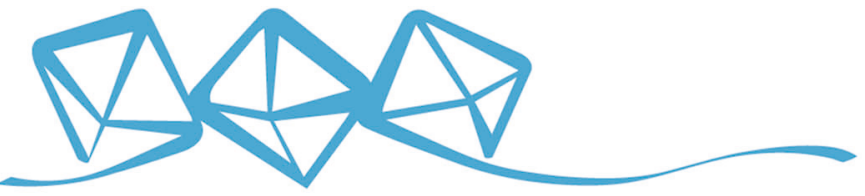 COMMUNICATIONS MATERIALS
}

ARTICLE

https://doi.org/10.1038/s43246-020-0036-z

OPEN

\section{Crystallisation control of drop-cast quasi-2D/3D perovskite layers for efficient solar cells}

Chuantian Zuo (1) ${ }^{1}$, Andrew D. Scully (1) ${ }^{1}$, Wen Liang Tan ${ }^{2}$, Fei Zheng ${ }^{3}$, Kenneth P. Ghiggino (i) ${ }^{3}$, Doojin Vak (D) ${ }^{1}$, Hasitha Weerasinghe ${ }^{1}$, Christopher R. McNeill (1) ${ }^{2}$, Dechan Angmo ${ }^{1}$, Anthony S. R. Chesman ${ }^{1} \&$ Mei Gao (i) ${ }^{1 凶}$

Introducing layered quasi-2D perovskite phases into a conventional 3D perovskite lightabsorbing matrix is a promising strategy for overcoming the limited environmental stability of 3D perovskite solar cells. Here, we present a simple drop-casting method for preparing hybrid perovskite films comprising both quasi-2D and quasi-3D phases, formed using phenylethylammonium or iso-butylammonium as spacer cations. The film morphology, phase purity, and crystal orientation of the hybrid quasi-2D/3D perovskite films are improved significantly by applying a simple $\mathrm{N}_{2}$ blow-drying step, together with inclusion of methylammonium chloride as an additive. An enhanced power conversion efficiency of $16.0 \%$ is achieved using an isobutylammonium-based quasi-2D/3D perovskite layer which, to our knowledge, is the highest recorded to date for a quasi-2D/3D perovskite solar cells containing a non-spin-cast perovskite layer prepared under ambient laboratory conditions.

\footnotetext{
${ }^{1}$ Flexible Electronics Laboratory, CSIRO Manufacturing, Clayton, VIC 3168, Australia. ${ }^{2}$ Department of Materials Science and Engineering, Monash University, Clayton, VIC 3800, Australia. ${ }^{3}$ School of Chemistry and ARC Centre of Excellence in Exciton Science, The University of Melbourne, Parkville, VIC 3010 ,

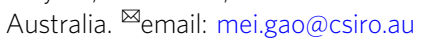


A fter ten years of rapid development, the record power conversion efficiency (PCE) for perovskite solar cells (PSCs) now exceeds 25\%, which is approaching the Shockley-Queisser limit and is competitive with the best singlejunction silicon solar cells ${ }^{1-5}$. Three-dimensional (3D) perovskite films demonstrate excellent optoelectronic properties, including strong light absorbance, low exciton binding energy and long charge-diffusion lengths, and they also allow for ease of deposition via solution-based processing methods. However, while the durability of 3D PSCs has been improved tremendously ${ }^{6,7}$, they remain prone to device performance degradation due to the presence of organic cations that are vulnerable to atmospheric moisture ${ }^{8}$. This has resulted in delays in the upscaling and commercialisation of this technology, requiring researchers to investigate related material classes that retain the same optoelectronic properties while also imparting greater stability to environmental exposure ${ }^{9,10}$.

Quasi-two-dimensional (2D) Ruddlesden-Popper perovskites, $\mathrm{R}_{2} \mathrm{~A}_{n-1} \mathrm{M}_{n} \mathrm{X}_{3 n+1}(n \geq 1)$, where $\mathrm{R}$ and $\mathrm{A}$ represent larger and smaller organic cations, respectively, $\mathrm{M}$ refers to transition metal cation (e.g. $\mathrm{Pb}^{+}$or $\mathrm{Sn}^{+}$) and $\mathrm{X}$ is a halide anion, are attracting increased attention for use in solar cells due to their higher operational stability compared with $3 \mathrm{D}$ perovskites ${ }^{11-15}$. The incorporation of bulkier organic cations with longer hydrocarbon chains between perovskite layers confers the material with hydrophobic properties that hinders moisture ingress, which ultimately improves environmental stability ${ }^{16}$. However, the use of $2 \mathrm{D}$ perovskite materials presents additional challenges in fabricating high-efficiency solar cells, as the crystal orientation in the photo-absorber film significantly affects the device performance. To overcome this, Tsai et al. developed a hot-casting spin-coating method for the preparation of films comprising highly oriented quasi-2D perovskites $\left(n-\mathrm{BA}_{2} \mathrm{MA}_{n-1} \mathrm{~Pb}_{n} \mathrm{I}_{3 n+1}\right)$, resulting in an improvement in PCE to $12.52 \%{ }^{13}$. Then quasi-2D perovskites with other cations such as phenylethylammonium (PEA) and isobutylammonium (iso-BA) were reported using spin coating with PCEs achieved around $11 \%{ }^{17,18}$. Subsequently, a series of alternative methods have been developed to further improve device performance, such as using different spacer cations (fluoro-phenylethylammonium (fluoro-PEA ${ }^{+}$), 1,4-butanediammonium $\left(\mathrm{BEA}^{2+}\right)$ ), optimising the $n$ value of the perovskite composition, and employing slow post-annealing conditions. These methods have significantly improved the quality of films containing the quasi-2D perovskites, and have pushed the PCEs of PSCs comprising quasi-2D perovskites beyond $17 \%{ }^{19-22}$.

Nevertheless, almost all PSCs comprising quasi-2D perovskites reported to date have been prepared by spin-coating in a glovebox, which is not suitable for upscaling. Recently, we reported a simple, low-waste, scalable method to prepare films based on quasi-2D perovskites in which a precursor solution was dropcasted on a heated substrate, and then spontaneously spreads to form a smooth, uniform film upon drying ${ }^{23}$. In that work, PSCs containing drop-cast n-butylammonium-based quasi-2D perovskites were the primary focus, with a PCE of $14.9 \%$ achieved for solar cells fabricated in an ambient environment. This result suggests that the drop-cast method is a promising route for producing high-efficiency solar cells in a scalable manner, and presented opportunities to increase PCE by using alternative organic cations and optimising the crystallisation process.

Herein we report a facile method to improve the performance of PSCs comprising quasi-2D perovskites using known cations, such as PEA and iso-BA. The application of a stream of air or nitrogen is used to dry the drop-cast films, with the incorporation of additional methylammonium chloride (MACl) additive further improving film quality. The same method is also applied for the preparation of $3 \mathrm{D}$ perovskites, and the difference in film formation using a quasi-2D perovskite precursor solution and that using a $3 \mathrm{D}$ perovskite $\mathrm{CH}_{3} \mathrm{NH}_{3} \mathrm{PbI}_{3}\left(\mathrm{MAPbI}_{3}\right)$ precursor solution is examined. The effect of the drying conditions and the presence of $\mathrm{MACl}$ additive on film morphology, phase purity and crystal orientation using the quasi-2D perovskite precursor solutions based on PEA or iso-BA spacer cations is investigated, and the photovoltaic performance of devices incorporating the drop-cast films is evaluated. The highest PCE of $16 \%$ was achieved for PSCs comprising $\mathrm{N}_{2}$ blow-dried iso-BA-based quasi$2 \mathrm{D}$ perovskite precursor solution.

\section{Results and discussion}

Film preparation methods. The preparation of films from $(\mathrm{PEA})_{2}(\mathrm{MA})_{4} \mathrm{~Pb}_{5} \mathrm{I}_{16}$ (PEA-2D) and (iso- $\left.\mathrm{BA}\right)_{2}(\mathrm{MA})_{4} \mathrm{~Pb}_{5} \mathrm{I}_{16}$ (isoBA-2D) precursor solutions is illustrated in Fig. 1. The perovskite precursor solution is drop-cast onto a pre-heated substrate (Fig. 1a), with the solution spreading spontaneously to form a circular wet film. Two methods are employed to dry the wet films: drying under ambient laboratory conditions, hereafter referred to as 'naturally dried' (Fig. 1b, c), and drying under a stream of nitrogen or air to accelerate the evaporation of the solvent, hereafter referred to ' $\mathrm{N}_{2}$ blow-dried' or 'air blow-dried', respectively, (Fig. 1d, e). These different drying processes lead to significantly different film qualities, as discussed in detail below.

Film morphology. Visual inspection of the drop-cast PEA-2D and iso-BA-2D films revealed significant differences in the appearance caused by the various drying techniques (Fig. 2). The $\mathrm{N}_{2}$ blow-dried films (Fig. 2c, d) look smoother and more uniform than their naturally dried counterparts, which appear grey and have several fringes on the surface (Fig. 2a, b). The morphology of the films was studied in greater detail using scanning electron microscopy (SEM) (Fig. 2e-f), with the naturally dried PEA-2D film (Fig. 2e) appearing rough and comprising some cylinder-like grains. The naturally dried iso-BA-2D film (Fig. 2f) also comprises cylinder-like grains, but its surface is considerably smoother. Both of these thin films exhibited severe microstructural defects with large pinholes leading to incomplete coverage of the substrate. In contrast, the PEA-2D and iso-BA-2D films prepared using $\mathrm{N}_{2}$ blow-drying present uniform, dense, and smooth surfaces (Fig. $2 \mathrm{~g}, \mathrm{~h}$ ). It should be noted that, as reported previously for spin-coated quasi-2D films ${ }^{19-21}$, the $\mathrm{N}_{2}$ blow-dried quasi-2D perovskite films do not display the granular features seen in 3D perovskite films. In contrast to cracks and pinholes often observed in the spin-cast quasi-2D perovskite films, there is little evidence of cracks and pinholes in the $\mathrm{N}_{2}$ blow-dried isoBA-2D perovskite films were produced in the present work (see Supplementary Fig. 1). The flow rate used during $\mathrm{N}_{2}$ blow-drying influences film quality, with optimisation of the $\mathrm{N}_{2}$ flow rate performed on iso-BA-2D films indicating that flow rates of at least $5 \mathrm{~L} \mathrm{~min}^{-1}$ are required to achieve uniform films (see Supplementary Fig. 2).

The difference in film morphology can be understood by considering the process of crystal growth ${ }^{24-27}$; the slower solvent evaporation during natural drying results in lower supersaturation and a low rate of nucleation, resulting in a low crystal nuclei concentration that causes the growth of fewer, larger grains. In contrast, $\mathrm{N}_{2}$ blow-drying causes rapid evaporation of the solvent, leading to high supersaturation and a high rate of nucleation. This ultimately causes the formation of highly uniform, compact films without defects (Fig. 1).

To compare the crystallisation process of the drop-cast PEA$2 \mathrm{D}$ and iso-BA-2D films with a conventional 3D perovskite system, $\mathrm{MAPbI}_{3}$ films were prepared using the same drop-casting methods (see Supplementary Fig. 3). Naturally dried $\mathrm{MAPbI}_{3}$ 


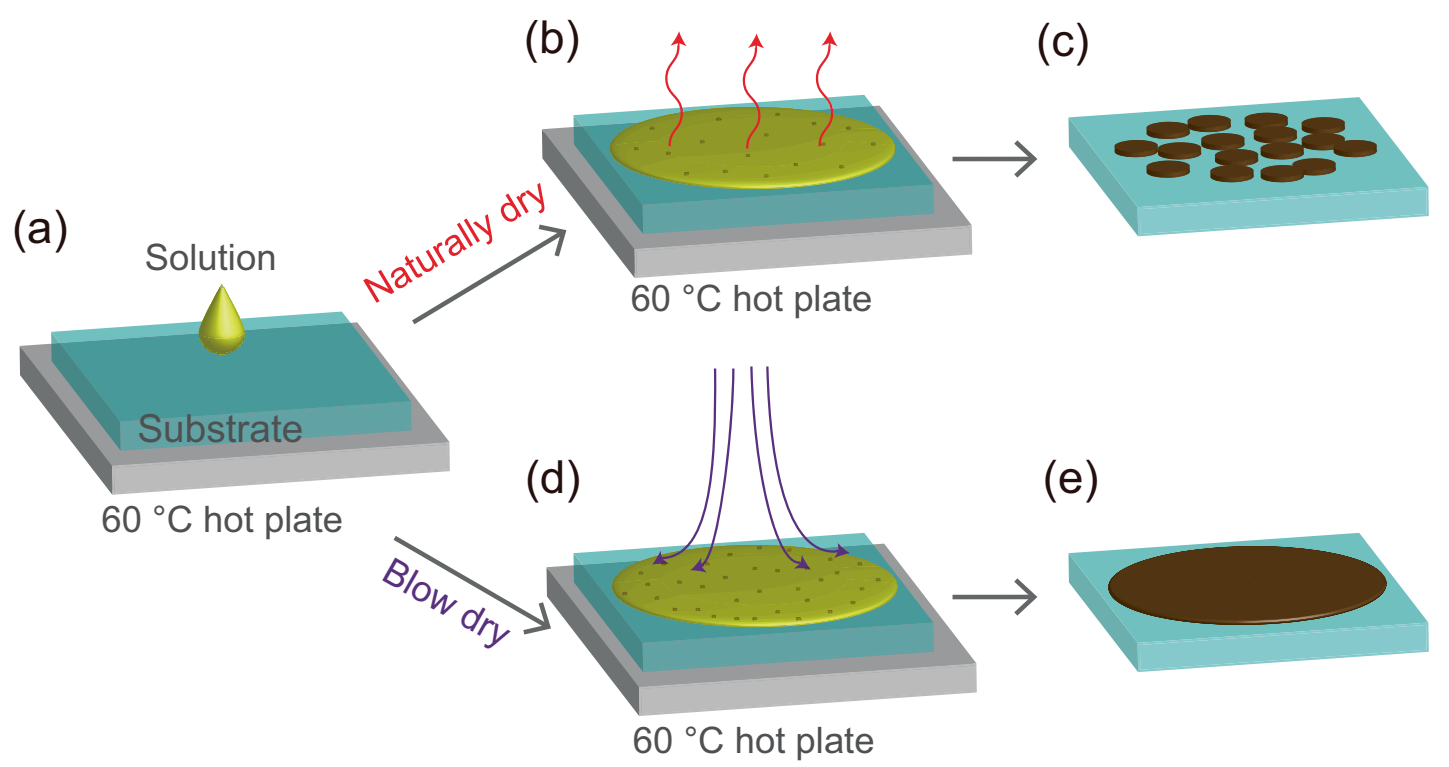

Fig. 1 Illustration of the natural drying and $\mathbf{N}_{\mathbf{2}}$ blow-drying processes used to prepare drop-cast quasi-2D perovskite films. a The 2D perovskite precursor solution is drop-cast onto a heated substrate. $\mathbf{b}$ The solution spreads spontaneously on the substrate and dries naturally; the supersaturation and number of crystal nuclei are low due to the slow drying. c The crystal nuclei grow into large crystal grains during drying. $\mathbf{d}$ The film spreads on the substrate and then an $\mathrm{N}_{2}$ stream is used to dry the film rapidly; the supersaturation and number of crystal nuclei is higher owing to the fast drying. e The crystal nuclei grow into a compact quasi-2D perovskite film.

PEA-2D

(a)

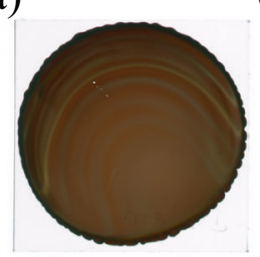

(c)

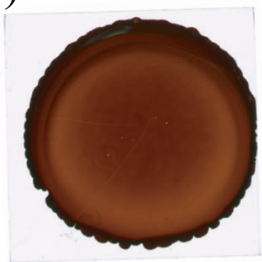

iso-BA-2D

(b)

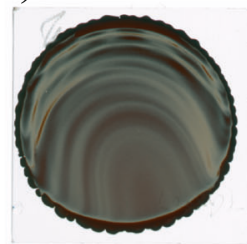

(d)

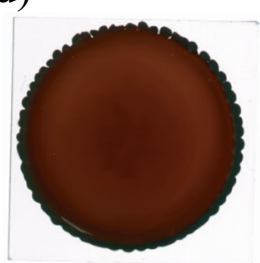

PEA-2D

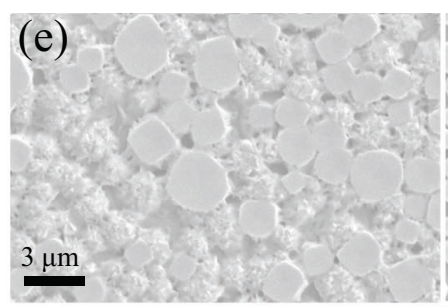

(g)

(h)

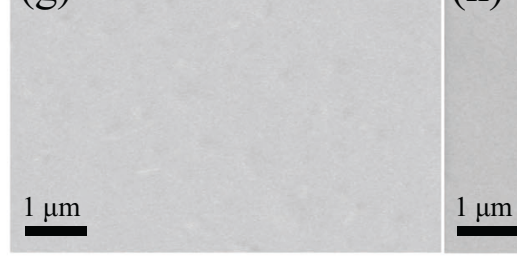

Fig. 2 Morphology of the drop-cast films prepared using different cations and conditions. Photographic images of $P E A-2 D$ and iso-BA-2D perovskite films prepared by natural drying $(\mathbf{a}, \mathbf{b})$ and $\mathrm{N}_{2}$ blow-drying $(\mathbf{c}, \mathbf{d})$; SEM images of PEA-2D and iso-BA-2D perovskite films prepared by natural drying (e, f) and $\mathrm{N}_{2}$ blow-drying $(\mathbf{g}, \mathbf{h})$.

films were rough, as found for the PEA-2D and iso-BA-2D films, and comprised needle-like grains, whereas $\mathrm{N}_{2}$ blow-drying yielded smoother films comprising more compact, smaller needle-like grains. However, the nucleation rate in the $\mathrm{MAPbI}_{3}$ wet disc is insufficient to give a pinhole-free film, and much higher $\mathrm{N}_{2}$ flow rates $\left(20 \mathrm{~L} \mathrm{~min}^{-1}\right.$ ) were required to form smooth and uniform regions at the centre of the film (see Supplementary Fig. $4 \mathrm{a}$ ), with the middle and edge of the films remaining nonuniform (see Supplementary Fig. 4b-d). The different properties of films formed using drop-casting quasi-2D and 3D perovskite precursor solutions suggest that cation size has a considerable impact on the nucleation of the perovskite crystals. In this regard, high-quality films containing quasi-2D perovskite can be prepared using milder $\mathrm{N}_{2}$ blow-drying. $\mathrm{MACl}$ is a popular additive used to improve the film quality of $3 \mathrm{D}$ perovskites ${ }^{28-30}$. However, addition of $\mathrm{MACl}$ has little effect on quasi-2D film morphology (see Supplementary Fig. 5) but has a profound effect on other film properties, as will be discussed below.

Phase distribution. UV-visible absorption spectroscopy was used to measure the optical properties of the films (see Supplementary Fig. 6). The high baseline in the spectra of the naturally dried films is due to light scattering resulting from the high degree of surface roughness of these films, but a number of excitonic absorption bands can be discerned, including the $n=1$ band in the naturally dried PEA-2D film. The $\mathrm{N}_{2}$ blow-dried films all 
(a)

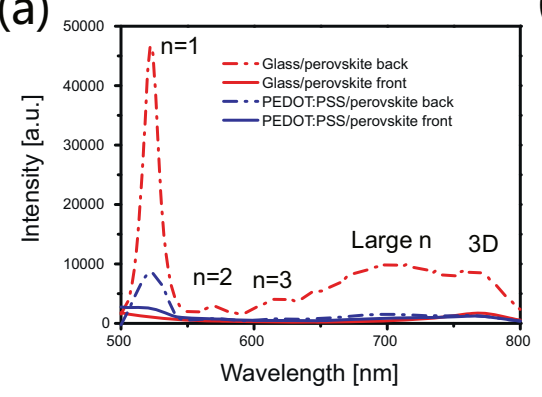

(d)

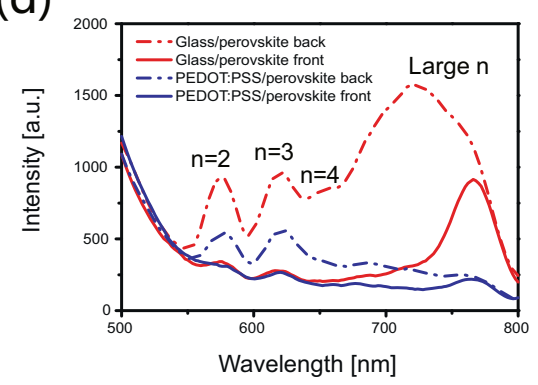

(b)

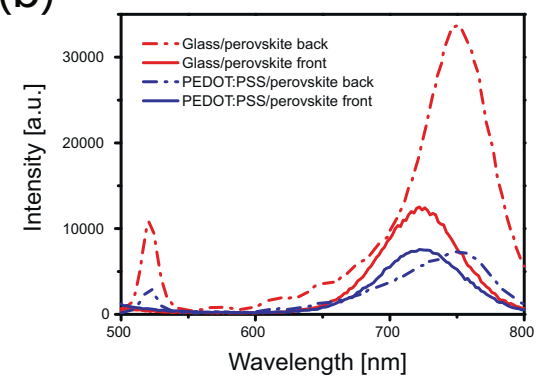

(e)

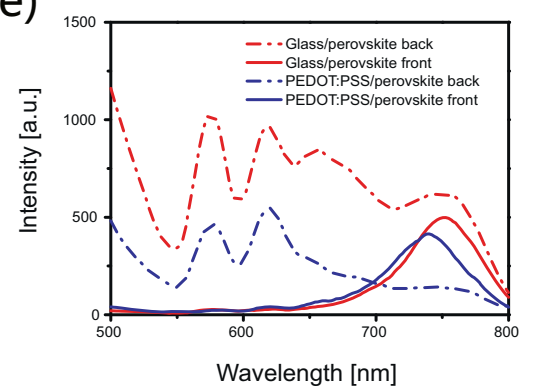

(c)

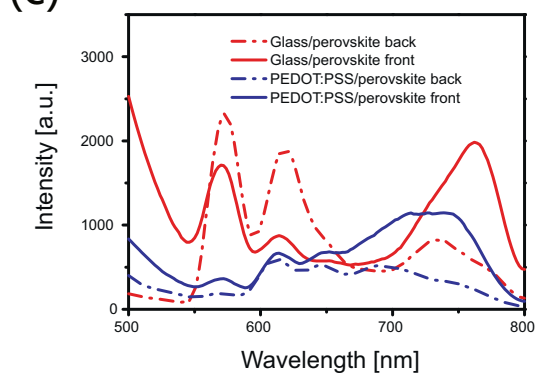

(f)

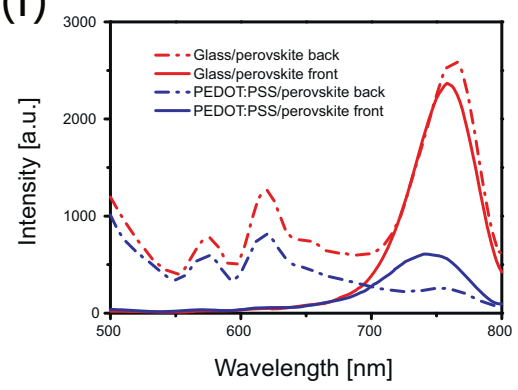

Fig. 3 Photoluminescence emission spectra of PEA-2D and iso-BA-2D perovskite films on glass and glass/PEDOT:PSS substrate (excitation: $440 \mathrm{~nm}$ ).

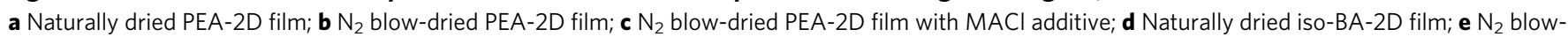
dried iso-BA-2D film; $\mathbf{f} \mathrm{N}_{2}$ blow-dried iso-BA-2D film with $\mathrm{MACl}$ additive.

display similar spectra with much less scattering and with distinct excitonic absorption peaks at 565, 608 and $643 \mathrm{~nm}$, which are characteristic of $n=2, n=3$ and $n=4$ phases, respectively ${ }^{31}$. The absorption onset at $763 \mathrm{~nm}$ is attributed to the co-formation of quasi-3D perovskite phases $(n \rightarrow \infty)$, highlighting the fact that the films produced from the quasi-2D perovskite precursor solutions in this work actually comprise a mixture of quasi-2D phases having a range of $n$ values, together with phases having sufficiently large $n$ values for the optical properties to approximate that of a conventional $3 \mathrm{D}$ phase, which will be referred to hereafter as quasi-2D/3D films. The $\mathrm{N}_{2}$ blow-dried films prepared with $\mathrm{MACl}$ additive show a slightly higher absorbance, which may be due to improved film quality. Similar results have been reported for spin-coated perovskite films ${ }^{32,33}$.

The photoluminescence (PL) emission spectra of the quasi-2D/ $3 \mathrm{D}$ perovskite films are shown in Fig. 3. The naturally dried PEA2D film displays PL maxima at 522, 574 and $619 \mathrm{~nm}$, corresponding to the $n=1, n=2$ and $n=3$ phases, respectively (Fig. 3a). The broad band extending between 650 and $750 \mathrm{~nm}$ is attributed to emission from multiple quasi-2D having $n>4$ and quasi-3D phases. For the $\mathrm{N}_{2}$ blow-dried PEA-2D film (Fig. 3b), the contribution from the quasi-2D phases decreases, with a corresponding increase in the $\mathrm{PL}$ from quasi-3D perovskite phases. For the PEA-2D film prepared using $\mathrm{MACl}$ additive (Fig. 3c), no $n=1$ peak is observed, and the PL from the $n=2$ and $n=3$ phases are relatively stronger than the other quasi-2D phases. For the iso-BA-2D films, the PL spectra have similar peaks for $n=2$ and $n=3$ phases, and no signal for the $n=1$ phase can be observed (Fig. $3 \mathrm{~d}-\mathrm{f}$ ). The broad band comprising overlapping peaks of the large $n$ phases is lower intensity for the $\mathrm{N}_{2}$ blow-dried film (Fig. 3e) than the naturally dried film (Fig. 3d). For the film prepared with $\mathrm{MACl}$ additive, the quasi-3D perovskite PL peaks become much stronger with an absence of any obvious peaks associated with quasi-2D $n>4$ phases (Fig. 3f), suggesting that the phases in the film become purer, being mainly composed of the quasi-2D $n=2, n=3, n=4$ phases and quasi$3 \mathrm{D}$ phases.
Comparison of the PL spectra excited from the back (glass) face and front (perovskite) face provides information about the vertical distribution of perovskite phases in the film. All films display markedly different PL spectra depending on excitation from the back or front face. The PL signal from small $n(n \leq 4)$ quasi-2D phases is much more pronounced for back-face excitation than front-face excitation, suggesting that there is a higher concentration of small $n$ quasi-2D phases forms at the bottom of the perovskite films, which is similarly observed in spin-coated films comprising quasi-2D perovskites ${ }^{19}$. Obvious PL quenching is observed for the films prepared on PEDOT:PSS, resulting from efficient hole transfer from the perovskite to PEDOT:PSS. The films prepared on glass and PEDOT:PSS show different peak positions for the quasi-3D phase, especially for the front excitation. The blueshift of PL peaks of quasi-3D phase suggests that the PL quenching of large $n$ phases may be more efficient than for small $n$ phases. There is no clear trend in the extent of PL quenching of the quasi-3D phase compared with the quasi-2D phases, with the exception of the front-face PL quenching of the quasi-3D phase in the iso-BA-2D film in which the PL quenching is improved significantly by using an $\mathrm{MACl}$ additive, suggesting improved hole transport through this film (Fig. 3f).

The effect of the $\mathrm{MACl}$ additive in the iso-BA-2D film was further investigated using time-resolved PL (TRPL) and transient absorption (TA) spectroscopy (Fig. 4). The iso-BA-2D perovskite film prepared on glass using the $\mathrm{MACl}$ additive shows an increased lifetime $(2.6 \mathrm{~ns})$ compared to the film without additive (0.9 ns), suggesting suppressed non-radiative charge-carrier recombination induced by trap-state passivation ${ }^{34}$. The TA spectra at selected pump-probe delay and the $2 \mathrm{D}$ contour plots (Fig. 4b and see Supplementary Fig. 7, respectively) show prominent ground-state bleaching (GB) peaks corresponding to the $n=2,3,4,5$ quasi-2D perovskite phases, and a broad GB band at wavelengths longer than $\sim 700 \mathrm{~nm}$ associated with bleaching of the quasi-3D phase, in good agreement with the band positions in the UV-visible absorption and PL spectra. The 

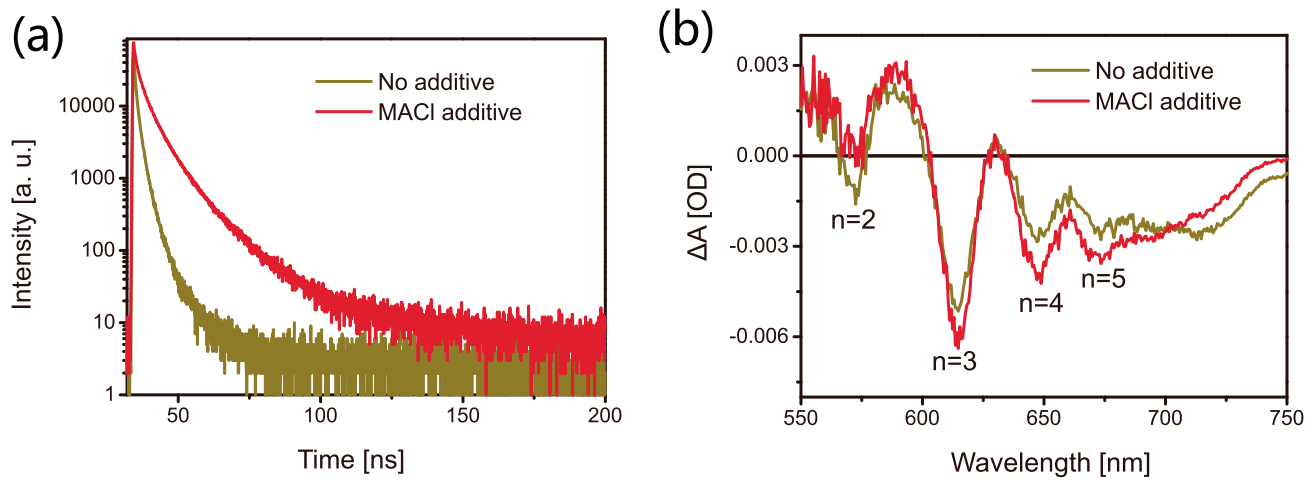

Fig. 4 Photophysics characterization of the drop-cast films. a Time-resolved photoluminescence decay (excitation: $400 \mathrm{~nm}$; emission: $>700 \mathrm{~nm}$ ) and b TA spectra at a delay time of $2 \mathrm{ps}$ (excitation: $510 \mathrm{~nm}$ ) for iso-BA-2D perovskite films on glass prepared by $\mathrm{N}_{2}$ blow-drying with and without $\mathrm{MACl}$ additive. For TRPL measurements, sample excitation and emission detection was from the glass (back) face. For TA, laser excitation was incident on the glass (back) face.

presence of the $\mathrm{MACl}$ additive appears to make little difference to the TA properties of the films. The evolution of the onset of the GB bands with increasing $n$ values seen in Supplementary Figs. 7 and 8 is consistent with energy cascading from the $n=2$ to $n=5$ quasi-2D phases before accumulating in the lowest energy quasi$3 \mathrm{D}$ phase, with the transfer of energy being essentially complete after about $100 \mathrm{ps}$, in good agreement with TA results reported by others for spin-cast films prepared from other quasi-2D $(\mathrm{PEA})_{2}(\mathrm{MA})_{2} \mathrm{~Pb}_{3} \mathrm{I}_{10}$ and $(\mathrm{NMA})_{2}(\mathrm{FA}) \mathrm{Pb}_{2} \mathrm{I}_{7}$ precursor solutions $(\mathrm{NMA}=1 \text {-naphthyl-methylammonium })^{35,36}$. The residual $\mathrm{PL}$ detected from each phase indicates the efficiency of energy transfer between phases is $<100 \%$. The progressive delay in the GB onset suggests that most of the 510-nm pump pulse incident at the back face of the film is absorbed primarily by the $n=2$ phase, with little/no absorption by higher $n$ phases. This implies there may be a degree of stratification throughout the perovskite layer, i.e. with $n=2$ primarily deposited at the base followed by layers of larger- $n$ phases, with the quasi-3D at the top.

Crystal orientation. The X-ray diffraction (XRD) patterns for the quasi-2D perovskite films are shown in Supplementary Fig. 9. The naturally dried PEA-2D film displays a weak peak at $5.3^{\circ}$, which is assigned to the 002 reflection of the $n=1$ phase $\left(\mathrm{PEA}_{2} \mathrm{PbI}_{4}\right)^{37}$. This peak is not observed in the $\mathrm{N}_{2}$ blow-dried film or the films prepared using $\mathrm{MACl}$ additive. All the films show many weak peaks which may be attributed to random crystal orientations. The iso-BA-2D films show nearly the same XRD patterns as the corresponding PEA-2D films but with only two main peaks (see Supplementary Fig. 9b), strongly suggesting that the crystals are highly oriented.

Synchrotron-based grazing incidence wide-angle X-ray scattering (GIWAXS) was performed to further investigate the crystal orientation in the film (Fig. 5). All the PEA-2D films exhibit scattering rings or arcs (rather than discrete spots), suggesting predominantly random orientation of the crystals in the film. Since the charge carriers in the lead halide perovskite are unable to transport through the insulating large cations, a crystal random orientation complicates the transportation of charge carriers through the film. In addition to peaks indexable to $3 \mathrm{D}$ phase, multiple scattering rings at low $q$ between 0.2 to $0.6 \AA^{-1}$ are seen which correspond to various low $n$ members of layered perovskite phases (see Supplementary Fig. 10). In particular, $n=1$ phase is clearly observed in the naturally dried PEA-2D film ${ }^{38}$. The $\mathrm{N}_{2}$ blow-dried PEA-2D film (without $\mathrm{MACl}$ ) exhibits extra scattering features correspond to layered perovskite phase of $n=1$ and 3, and additional intermediate or metastable phase ${ }^{39}$. Interestingly, these scattering peaks are greatly suppressed in the blow-dried
PEA-2D film prepared with $\mathrm{MACl}$, leaving relatively weak peaks correspond to $n=1$ phase.

In contrast to the relatively random orientation of the PEA-2D films, all iso-BA-2D films show concentrated Bragg spots indicating highly textured films (Fig. 5d-f). To determine the crystal orientation, the experimental GIWAXS patterns were compared with the simulated patterns assuming two distinct crystallographic orientations (see Supplementary Fig. 11). We confirm the vertical orientation of the bulkier organic cation layers to the substrate from the excellent agreement of the strong as well as the weak Bragg reflections (see Supplementary Fig. 11). The missing in-plane scatterings correspond to the $0 k 0$ reflections is possibly due to the presence of other low $n$ phase disrupting the structural ordering of $n=4$ phase, or being hidden by the substrate horizon due to the highly textured nature of the film. Compared to naturally dried iso-BA-2D film, the $\mathrm{N}_{2}$-dried films show Bragg spots with much lower azimuthal spreading of diffracted intensity, indicating improved crystal orientation. Further analysis on the pole figure along $q=1.7 \AA^{-1}$ in Supplementary Fig. 12 confirms an improvement in the overall texture of the $\mathrm{N}_{2}$-dried film, with the fraction of crystallites exhibiting a high degree of texture increasing from $54 \%$ to $85 \%$ upon $\mathrm{N}_{2}$ drying. Comparing the GIWAXS patterns of the iso-BA2D films to the simulated patterns, additional peaks are seen as indicated by arrows in Fig. 5d-f that are not indexable to a perovskite or Ruddlesden-Popper phase. Comparing 1D sector plots in Supplementary Fig. 13 reveals that the additional phase is more prevalent in the blow-dried film as compared to the naturally dried film. Furthermore, the use of the $\mathrm{MACl}$ additive also appears to suppress the abundance of this phase. The additional phase is proposed to be an unresolved intermediate phase with the amount of residual intermediate phase present related to the crystallisation kinetics. $\mathrm{N}_{2}$ drying accelerates the solvent removal process as compared to natural drying, resulting in a faster crystallisation kinetics and more residual intermediate phase. The addition of $\mathrm{MACl}$ had been reported to slow the perovskite crystallisation process, thereby resulting in less residual intermediate phase ${ }^{28-30}$. The near-perfect vertical orientation (see Supplementary Fig. 14) of the 2D perovskite crystals in the BA2D films with respect to the substrate will be beneficial for chargecarrier transport ${ }^{40}$ and may help to explain the improved PL quenching in the $\mathrm{N}_{2}$-dried iso-BA-2D film with $\mathrm{MACl}$ additive.

Photovoltaic performance. The performance of drop-cast PEA$2 \mathrm{D}$ and iso-BA-2D perovskite layers in solar cells was investigated using devices comprising ITO/modified-PEDOT:PSS (mPEDOT:PSS)/quasi-2D perovskite/PC ${ }_{61} \mathrm{BM} / \mathrm{PEIE} / \mathrm{Ag}$ (Fig. 6a), 
(a)
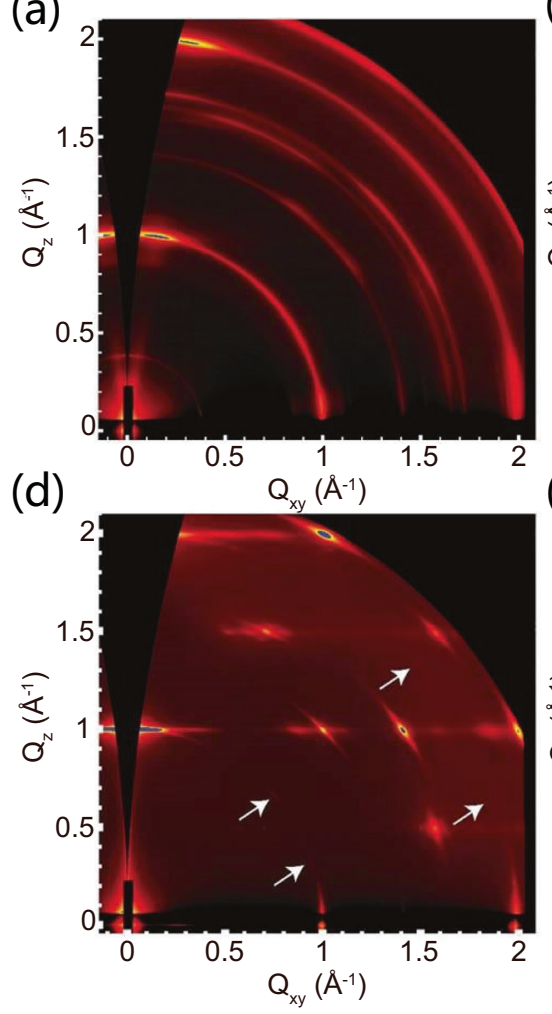

(b)

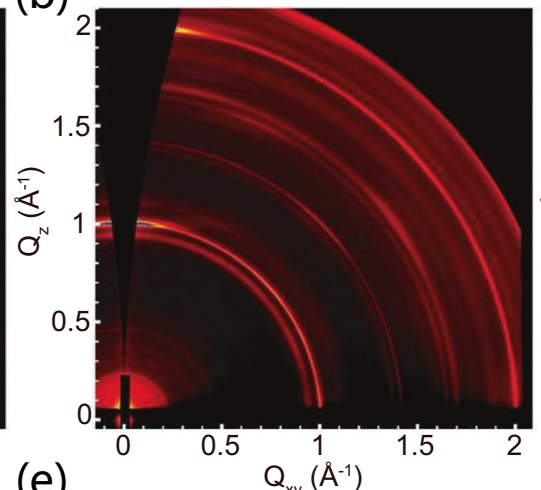

(e)

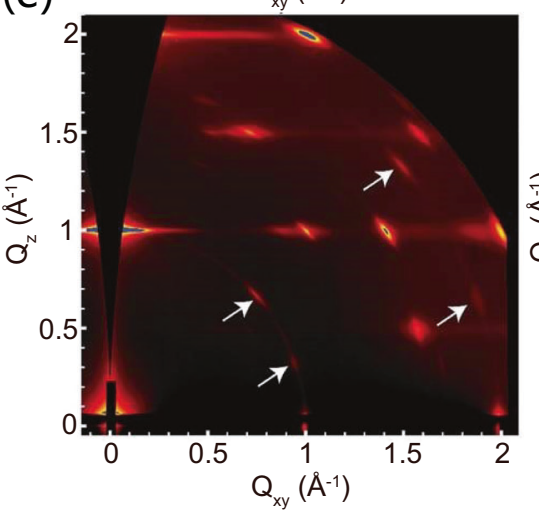

(c)

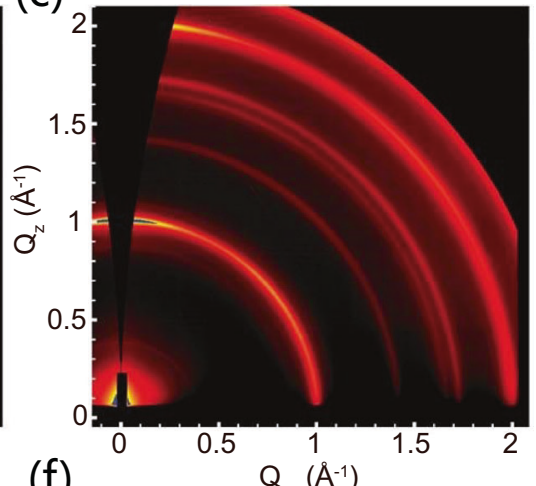

(f)

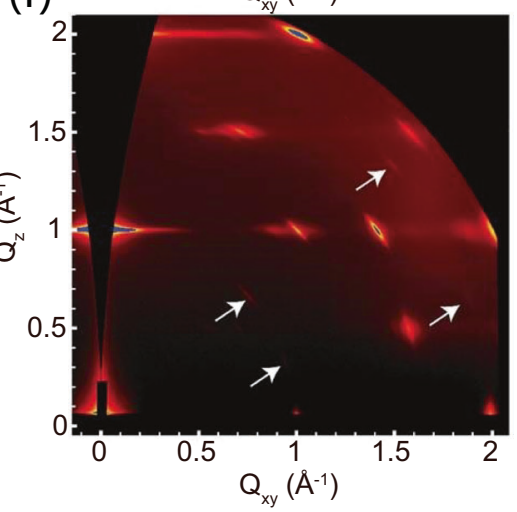

Fig. 5 GIWAXS patterns for drop-cast PEA-2D and iso-BA-2D perovskite films. a Naturally dried PEA-2D film; $\mathbf{b} \mathrm{N}_{2}$ blow-dried PEA-2D film; c $\mathrm{N}_{2}$ blowdried PEA-2D film with $\mathrm{MACl}$ additive; $\mathbf{d}$ naturally dried iso-BA-2D film; e $\mathrm{N}_{2}$ blow-dried iso-BA-2D film; $\mathbf{f} \mathrm{N}_{2}$ blow-dried iso-BA-2D film with $\mathrm{MACl}$ additive.

(a)

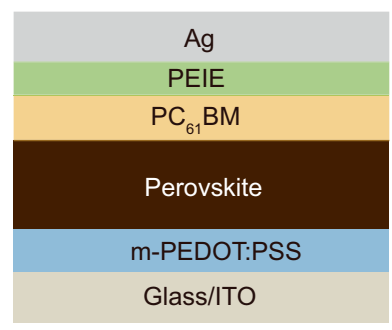

(d)

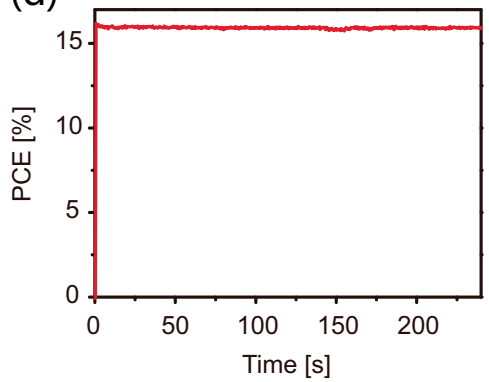

(b)

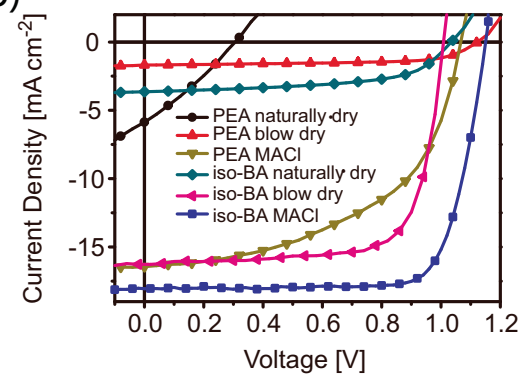

(e)

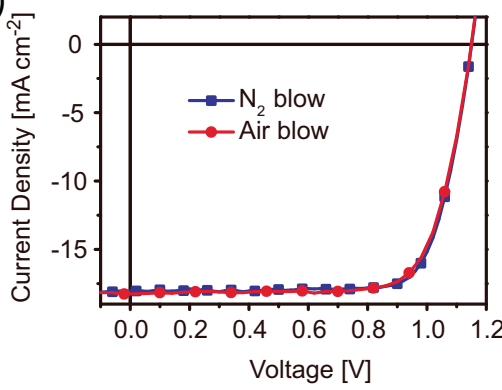

(c)

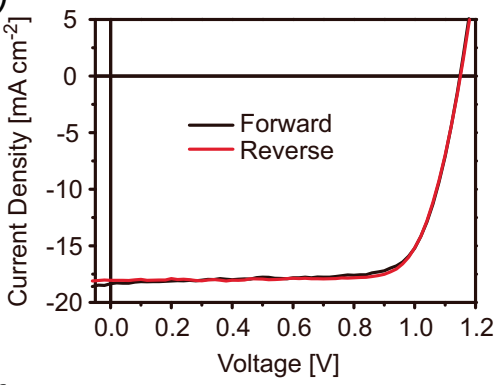

(f)

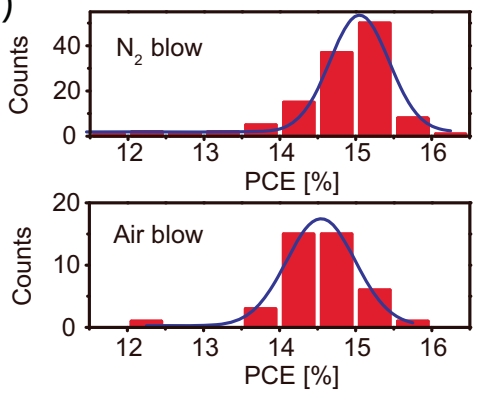

Fig. 6 Device performance of perovskite solar cells prepared using different conditions. a Device structure of the quasi-2D perovskite solar cells; $\mathbf{b} J-V$ curves for the PEA-2D and iso-BA-2D perovskite solar cells prepared by natural drying, and $\mathrm{N}_{2}$ blow-drying with and without $\mathrm{MACl}$ additive; $\mathrm{c} J-\mathrm{V}$ curves for the 'champion' cell under reverse and forward scan; $\mathbf{d}$ PCE obtained using MPP tracking; $\mathbf{e} J-V$ curves for the 'champion' cells prepared by drying under $\mathrm{N}_{2}$ or air streams; $\mathbf{f}$ statistics of the PCE distribution for iso-BA-2D perovskite solar cells prepared by drying under $\mathrm{N}_{2}$ or air streams. 
Table 1 Performance of solar cells using different cations and drying methods.

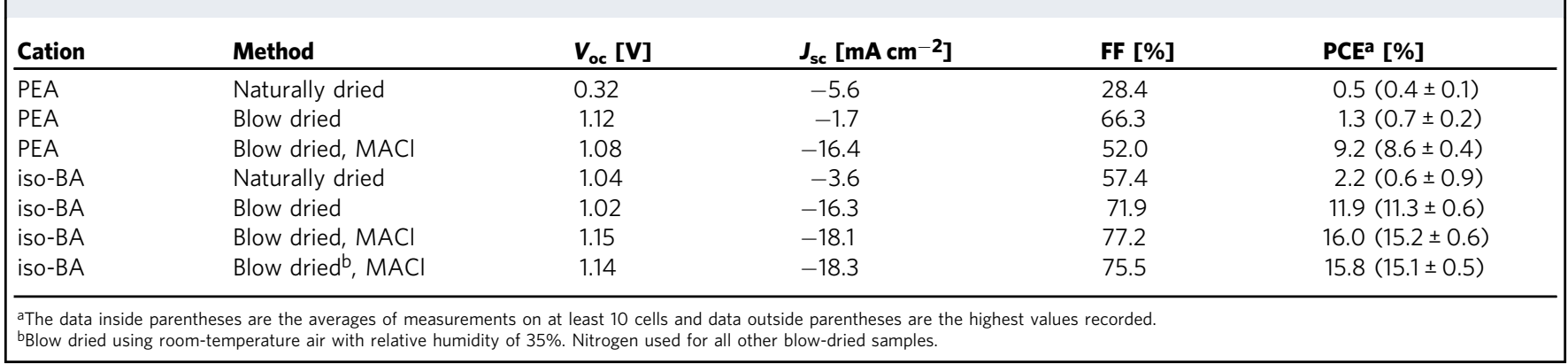

which were fabricated completely under ambient laboratory conditions (see Methods section), with m-PEDOT:PSS being used instead of PEDOT:PSS to obtain a higher open-circuit voltage $\left(V_{\mathrm{oc}}\right)^{41,42} \cdot \mathrm{N}_{2}$ flow rate was optimised using iso-BA-2D perovskite (see Supplementary Table 1). The best performance was obtained using a flow rate of $10 \mathrm{~L} \mathrm{~min}^{-1}$, with little effect on device performance on using higher flow rates. The cells fabricated using naturally dried and $\mathrm{N}_{2}$ blow-dried PEA-2D perovskite films show very low short-circuit current $\left(J_{\text {sc }}\right)$ and PCE (Fig. 6b, Table 1). This may be due to the $n=1$ phase at the base of the photoabsorber film blocking hole transport to the m-PEDOT:PSS layer. A demonstrable improvement in $J_{\mathrm{sc}}$ and PCE was found for cells fabricated using $\mathrm{N}_{2}$ blow-dried PEA-2D perovskite films with $\mathrm{MACl}$ additive, which is attributed to improved charge transport associated with the elimination of the $n=1$ phase.

Cells incorporating naturally dried iso-BA-2D perovskite films also showed very low PCE (2.2\%), which is attributed to the discontinuous coverage of the perovskite layer allowing recombination between the hole transport layer (m-PEDOT:PSS) and the electron transport layer $\left(\mathrm{PC}_{61} \mathrm{BM}\right)$. The device comprising a compact $\mathrm{N}_{2}$ blow-dried film generated higher $J_{\mathrm{sc}}\left(16.3 \mathrm{~mA} \mathrm{~cm}^{-2}\right)$, FF (71.9\%) and PCE (11.9\%), and the addition of $\mathrm{MACl}$ improved the PCE to $16.0 \%$, with a higher $V_{\mathrm{oc}}$ of $1.15 \mathrm{~V}$, a $J_{\mathrm{sc}}$ of $18.1 \mathrm{~mA} \mathrm{~cm}^{-2}$ and an FF of $77.2 \%$. The PCE is much higher than the previous achieved PCE (10.6\%) of iso-BA-2D PSCs prepared by spin coating ${ }^{17}$. This is ascribed to improved phase purity and crystal orientation, which facilitates charge transport in the perovskite layer. Furthermore, a low level of hysteresis is observed in the current density-voltage $(J-V)$ curves obtained in forward and reverse scans (Fig. 6c). The steady-state PCE of the 'champion' cell recorded using maximum power point (MPP) tracking (Fig. 6d) was $15.9 \%$, consistent with the $J-V$ measurement. The PCE of an encapsulated cell retains $91 \%$ of the initial value after $500 \mathrm{~h}$ of continuous 1-sun illumination, indicating good device durability (see Supplementary Fig. 15).

The performance of the cells using iso-BA-2D perovskite prepared by air blow-drying was also investigated. As discussed above, the formation of high-quality iso-BA-2D perovskite films does not require a high flow rate, and effective drying can be achieved with a conventional hair dryer that does not produce heat. The best cell incorporating an air-dried iso-BA-2D perovskite layer gave a $V_{\mathrm{oc}}$ of $1.14 \mathrm{~V}$, a $J_{\mathrm{sc}}$ of $18.3 \mathrm{~mA} \mathrm{~cm}^{-2}$, an FF of $75.5 \%$ and a PCE of $15.8 \%$, which is very close to the values achieved using $\mathrm{N}_{2}$ blow-drying (Fig. 6e, Table 1).

The performance reproducibility of the cells using $\mathrm{N}_{2}$ blowdrying or air blow-drying (relative humidity $35 \%$ ) was also investigated (Fig. 6f). Most of these cells displayed PCEs in the $14.5-15.5 \%$ and $14-15 \%$ ranges, respectively, demonstrating a high degree of reproducibility. The ease of using air-drying rather than an $\mathrm{N}_{2}$ source not only significantly reduces the cost of the process but also addresses the operational safety concerns of using an asphyxiant, which is an important consideration in large-scale manufacturing.

A roll-to-roll (R2R) slot-die coating process was used to demonstrate the scalable production of the iso-BA-2D perovskite film (Fig. 7a). Some pinholes can be observed in the SEM image (see Supplementary Fig. 16), and the film was not as uniform as on a glass substrate, which is possibly due to the rougher and less hydrophilic surface of the ITO/PET substrate leading to dewetting on the substrate. Perovskite solar cells with the same device structure as the drop-cast method were produced using R2R slot-die process to deposit the perovskite layer; the 'champion' cell displayed a $V_{\text {oc }}$ of $1.04 \mathrm{~V}$, a $J_{\mathrm{sc}}$ of $13.6 \mathrm{~mA} \mathrm{~cm} \mathrm{~cm}^{-2}$, an FF of $66.0 \%$ and a PCE of $9.3 \%$, which is a $14 \%$ improvement from our previously reported PCE of $8 \%{ }^{23}$. This demonstrates the potential for these materials to be incorporated into a facile, mass-production fabrication process, with higher PCEs anticipated from the use of substrates having a more hydrophilic and smoother surface, and lower sheet resistance. Cleaning the substrate using plasma treatment and protecting coatings from scratching may further improve the device performance.

In summary, we have demonstrated a simple drop-casting method to prepare quasi-2D/3D perovskite films with PEA and iso-BA cations. In comparison with the $3 \mathrm{D} \mathrm{MAPbI}_{3}$ perovskite, we found that the use of these large cations assists in the formation of uniform films. $\mathrm{N}_{2}$ blow-drying and $\mathrm{MACl}$ additive were used to control the crystallisation process and improve the film quality. The $\mathrm{N}_{2}$ blow-drying accelerates solvent evaporation, increasing the supersaturation and nucleation of solution, resulting in a compact and smooth film. The $\mathrm{MACl}$ additive can suppress the formation of the $n=1$ phase of PEA-2D perovskite. For the iso-BA-2D perovskite, the $\mathrm{MACl}$ additive improves the phase purity and crystal orientation, leading to significantly improved device performance. GIWAX results suggest that the PEA-2D perovskite film is randomly orientated, while the iso-BA-2D film is highly vertically orientated, which is favourable for charge transport in high-performance devices. The staggered bleaching onset in TA measurements suggest that there may be a degree of stratification in the phase distribution in iso-BA-2D films, with $n=2$ preferentially locating at the glass surface with $n$ systematically increasing away from the glass surface, with quasi-3D phases concentrated at the top face of the film. PCEs of $9.2 \%$ and $16.0 \%$ were achieved using $\mathrm{N}_{2}$ blowdried PEA-2D and iso-BA-2D films, respectively. Drying using a stream of humid air (relative humidity: $35 \%$ ) was also investigated and a PCE of $15.8 \%$ was achieved. Translation from batch to a continuous $\mathrm{R} 2 \mathrm{R}$ process was successfully demonstrated, achieving a maximum PCE of $9.3 \%$ for solar cells on a flexible substrate. This enhanced performance demonstrates the viability of using an R2R-compatible method to fabricate high-performance quasi-2D/3D perovskite layers under ambient laboratory conditions. 
(a)

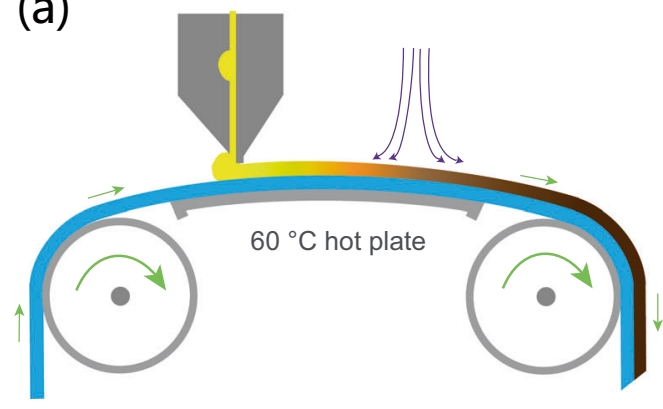

(b)

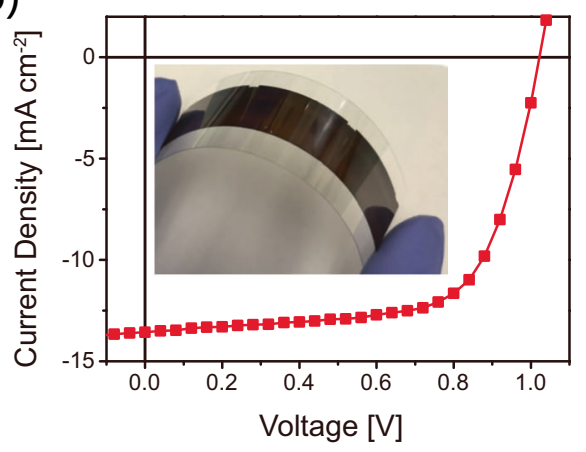

Fig. 7 R2R slot-die coating and device performance for the 2D perovskite film. a R2R slot-die coating of a 2D perovskite film; $\mathbf{b}$ the $J-V$ curve for a champion perovskite solar cell and photograph of the iso-BA-2D perovskite film prepared using the R2R process (inset).

\begin{abstract}
Methods
General information. All materials were purchased and used without further purification unless specified. Dimethylformamide (DMF) (Sigma Aldrich, 99.5\%), $\mathrm{MACl}(99 \%)$ and sodium polystyrene sulfonate (MW 70,000) were purchased from Sigma Aldrich. $\mathrm{PbI}_{2}$ was purchased from TCI. $\mathrm{PC}_{61} \mathrm{BM}(99 \%)$ was purchased from Ossila. MAI, iso-BAI and PEAI were purchased from GreatCell Solar. PEDOT:PSS (Baytron P AI 4083) was purchased from HC Starck. Acetone and isopropanol were purchased from Merck.
\end{abstract}

Solution preparation. Precursor solutions for $(\mathrm{PEA})_{2}(\mathrm{MA})_{4} \mathrm{~Pb}_{5} \mathrm{I}_{16}$ and (iso$\mathrm{BA})_{2}(\mathrm{MA})_{4} \mathrm{~Pb}_{5} \mathrm{I}_{16}$ had $0.3 \mathrm{M} \mathrm{Pb}^{2+}$ concentrations and the $\mathrm{PbI}_{2}: \mathrm{MAI}$ :iso-BAI or PEAI reagent ratios were 5:4:2. The reagents were dissolved in anhydrous DMF and stirred at $70^{\circ} \mathrm{C}$ for $1 \mathrm{~h}$. $\mathrm{MACl}$ was then added to the precursors at a concentration of 2 and $1 \mathrm{mg} \mathrm{mL}^{-1}$ for the PEA and iso-BA perovskite solutions, respectively. $\mathrm{MAPbI}_{3}$ precursor solutions for films prepared using low $\mathrm{N}_{2}$ flow rate (Supplementary Fig. 3) were prepared by dissolving $0.3 \mathrm{M}$ each of $\mathrm{PbI}_{2}$ and MAI in DMF by stirring at $70^{\circ} \mathrm{C}$ for $1 \mathrm{~h} . \mathrm{MAPbI}_{3}$ precursor solutions for films prepared using high $\mathrm{N}_{2}$ flow rate (Supplementary Fig. 4) were prepared by dissolving $1 \mathrm{M}$ each of $\mathrm{PbI}_{2}$ and MAI in DMF by stirring at $70^{\circ} \mathrm{C}$ for $1 \mathrm{~h}$. The m-PEDOT:PSS solution for spin coating was prepared by mixing $0.5 \mathrm{~mL}$ as-provided PEDOT:PSS, $15 \mathrm{mg}$ sodium polystyrene sulfonate and $2.5 \mathrm{~mL}$ of deionized water with stirring for 10 $\mathrm{min}$ at room temperature. The m-PEDOT:PSS solution for R2R slot-die coating was prepared by mixing $0.5 \mathrm{~mL}$ PEDOT:PSS, $15 \mathrm{mg}$ sodium polystyrene sulfonate and $1.5 \mathrm{~mL}$ deionized water with stirring for $10 \mathrm{~min}$, and then adding $1.6 \mathrm{~mL}$ of isopropanol into the solution with additional stirring.

Materials characterisation. UV-visible absorption spectra were recorded using a Hewlett-Packard/Agilent 8453 UV-vis Spectrophotometer (300-1100 nm). PL spectra were recorded using a luminescence spectrometer (Edinburgh Instruments, FLSP920) with a CW Xe lamp $\left(\sim 0.1 \mathrm{~mW} \mathrm{~cm}^{-2}\right)$ as the excitation source. TRPL measurements were performed using a TCSPC setup, which consists of $400 \mathrm{~nm}$ $(1 \mathrm{MHz}, 100 \mathrm{fs}$ FWHM) pulsed-laser excitation with excitation pulse fluence of $40 \mu \mathrm{J} \mathrm{cm}^{-2}$ and a commercial photon counting system (SPC150 card, B\&H, Germany) as the detector. Femtosecond pump-probe TA measurements on films with $510 \mathrm{~nm}(\mathrm{FWHM}<20 \mathrm{~nm})$ excitation were performed at room temperature using an in-house TA spectrometer system. A 60 fs laser pulse at $800 \mathrm{~nm}(96 \mathrm{kHz})$ was used to generate the $510 \mathrm{~nm}$ pump beam and white light probe beam separately. The pump and probe pulses were focused on the back (glass) face of film samples with an off-axis parabolic mirror, with the fluence of pump beam set to be $0.52 \mu \mathrm{J} \mathrm{cm}-2$ at the excitation point. The time-resolved TA spectra were recorded using the visible version of an Ultrafast Systems high-speed fibre-optic spectrometer. 'De-chirping' correction was performed using Surface Xplorer software by specifying four time zero-wavelength pairs in the chirp correction mode. XRD measurements were performed using a Rigaku SmartLab with $\mathrm{Cu} K_{\alpha}$ radiation. GIWAXS measurements were performed at the SAXS/WAXS beamline at the Australian Synchrotron ${ }^{43}$. The energy of X-ray incident beam was fixed at $15 \mathrm{keV}$. 2D scattering patterns were recorded by an in-vacuum Pilatus $2 \mathrm{M}$ detector placed $\sim 72 \mathrm{~cm}$ from the sample position, with a $0.40^{\circ}$ incident angle and a total exposure time of $3 \mathrm{~s}$. The sample-todetector distance was calibrated with a silver behenate sample. The scattering results were analysed using Igor Pro with an altered version of NIKA analysis package ${ }^{44}$. The simulation of GIWAXS patterns was done using GIXSGUI up to $q=2 \AA^{-1}$ (ref. ${ }^{45}$ ). Extremely weak Bragg reflections (theoretical intensity less than 1 based on the calculated powder XRD intensity using VESTA software ${ }^{46}$ ) were not shown in the simulated GIWAXS patterns. The SEM images of the films were taken with a Zeiss Merlin field emission SEM (FE-SEM) operated at an accelerating voltage of $5 \mathrm{kV}$.
Device fabrication. Perovskite solar cells made using the drop-cast method. Patterned ITO-coated glass $(25 \mathrm{~mm} \times 25 \mathrm{~mm}$ ) was cleaned in detergent (Deconex 12PA detergent solution), deionized water, acetone and isopropanol sequentially by ultrasonication and then treated with UV-ozone for $15 \mathrm{~min}$. m-PEDOT:PSS was spin coated at 5000 r.p.m. for $30 \mathrm{~s}$. The substrate was then heated on a hot plate at $150^{\circ} \mathrm{C}$ for $10 \mathrm{~min}$ in air. After cooling to room temperature, the substrate was placed on a hot plate heated to $60^{\circ} \mathrm{C}$ for $2 \mathrm{~min}$, after which $6 \mu \mathrm{L}$ of the perovskite precursor solutions $\left(0.3 \mathrm{M} \mathrm{Pb}^{2+}\right)$ was deposited onto the centre of the substrate. The solution spread on the substrate to form a circular wet film. For films prepared by drying under ambient conditions, no additional treatment was applied. For films prepared by $\mathrm{N}_{2}$ blow-drying, a stream of nitrogen was applied to the film when it started to dry (the edge of the wet film turns black), resulting in the near-immediate drying of the entire film, giving a dark brown film. The $\mathrm{N}_{2}$ was delivered via a plastic tube with an inner diameter of $4 \mathrm{~mm}$. The tube was perpendicular to the substrate and the outlet of the tube was located $10 \mathrm{~cm}$ above the substrate. The flow rate of the $\mathrm{N}_{2}$ gas was adjusted using a flowmeter. For films prepared by air-drying, a hair dryer was used to blow the film at room temperature (relatively humidity $35 \%$ ) After $\mathrm{N}_{2}$ or air blow-drying, the substrate was heated at $100^{\circ} \mathrm{C}$ for $2 \mathrm{~min}$. After cooling to room temperature, $70 \mu \mathrm{L} \mathrm{PC}_{61} \mathrm{BM}$ in chloroform $\left(10 \mathrm{mg} \mathrm{mL}^{-1}\right)$ was spin coated onto the $2 \mathrm{D}$ perovskite layer at 1000 r.p.m. for $30 \mathrm{~s}$. Then polyethylenimine ethoxylated (PEIE) $\left(0.05 \% \mathrm{w} / \mathrm{w}\right.$ in isopropanol) was spin coated onto the $\mathrm{PC}_{61} \mathrm{BM}$ layer at 4000 r.p.m. for $30 \mathrm{~s}$. Finally, $100 \mathrm{~nm} \mathrm{Ag}$ was evaporated through a shadow mask to give an active area of $0.1 \mathrm{~cm}^{2}$.

Perovskite solar cells made using R2R slot-die coating. The setup of the printer and the coating of the PEDOT:PSS layer can be found in our previous work ${ }^{42}$. A (iso- $\mathrm{BA})_{2}(\mathrm{MA})_{4} \mathrm{~Pb}_{5} \mathrm{I}_{16}$ precursor solution containing $0.7 \mathrm{M} \mathrm{Pb}^{2+}$ was used. The speed of the substrate movement was $0.5 \mathrm{~m} \mathrm{~min}^{-1}$ and the solution feed speed was $30 \mu \mathrm{L} \mathrm{min}{ }^{-1}$. The coated film was passed over the first curved hot plate at $60^{\circ} \mathrm{C}$ to dry the film, and then over a second hot plate at $100^{\circ} \mathrm{C}$, before being collected in a roll. After completing the perovskite layer, the substrate was cut into $25 \mathrm{~mm} \times 25$ $\mathrm{mm}$ to make solar cells. $\mathrm{PC}_{61} \mathrm{BM}$, PEIE and Ag layers were deposited as described above.

Device PV measurements. The $J-V$ curves were measured under an inert atmosphere without extra temperature control using a Keithley 2400 Source Meter under standard solar irradiation (AM 1.5G, $100 \mathrm{~mW} \mathrm{~cm}^{-2}$ ). The light source of Xe lamp with AM 1.5G solar filter is from Newport Model 67005. The light intensity was calibrated using a reference cell (Hamamatsu S1133 with KG5 filter, $2.8 \times 2.4 \mathrm{~mm}$ of photosensitive area), which was calibrated by a certified reference cell (PV Measurements, certified by NREL with KG5 filter) under $1000 \mathrm{~W} \mathrm{~m}^{-2}$ AM $1.5 \mathrm{G}$ illumination from an Oriel AAA solar simulator fitted with a $1000 \mathrm{~W}$ Xe lamp.

For the stability test under continuous illumination. The cell was encapsulated in an $\mathrm{N}_{2}$ filled glovebox by covering a glass-lid onto the device with UV curable epoxy (Supplementary Fig. 16). Stability tests were conducted using the Candlelight Maximum power tracker. The encapsulated devices were loaded in a device chamber and then were exposed to 1 -sun conditions. $J-V$ characteristics of the devices and the temperature and the relative humidity inside the devices chamber were recoded after every $10 \mathrm{~min}$.

Reporting summary. Further information on experimental design is available in the Nature Research Reporting Summary linked to this paper.

\section{Data availability}

The data that support the findings of this study are available on reasonable request from the corresponding author. 
Received: 28 January 2020; Accepted: 18 May 2020;

Published online: 05 June 2020

\section{References}

1. Kojima, A., Teshima, K., Shirai, Y. \& Miyasaka, T. Organometal halide perovskites as visible-light sensitizers for photovoltaic cells. J. Am. Chem. Soc. 131, 6050-6051 (2009)

2. Lee, M. M., Teuscher, J., Miyasaka, T., Murakami, T. N. \& Snaith, H. J. Efficient hybrid solar cells based on meso-superstructured organometal halide perovskites. Science 338, 643-647 (2012).

3. Green, M. A., Ho-Baillie, A. \& Snaith, H. J. The emergence of perovskite solar cells. Nat. Photonics 8, 506-514 (2014).

4. Jiang, Q. et al. Surface passivation of perovskite film for efficient solar cells. Nat. Photonics https://doi.org/10.1038/s41566-019-0398-2 (2019).

5. Burschka, J. et al. Sequential deposition as a route to high-performance perovskite-sensitized solar cells. Nature 499, 316-319 (2013).

6. Rong, Y. et al. Challenges for commercializing perovskite solar cells. Science 361, 1214 (2018)

7. Jia, X. et al. $\mathrm{CsPb}\left(\mathrm{I}_{\mathrm{x}} \mathrm{Br}_{1-\mathrm{x}}\right)_{3}$ solar cells. Sci. Bull. 64, 1532-1539 (2019).

8. Niu, G., Guo, X. \& Wang, L. Review of recent progress in chemical stability of perovskite solar cells. J. Mater. Chem. A 3, 8970-8980 (2015)

9. Galagan, Y. Perovskite solar cells: toward industrial-scale methods. J. Phys. Chem. Lett. 9, 4326-4335 (2018).

10. Li, Z. et al. Scalable fabrication of perovskite solar cells. Nat. Rev. Mater. 3, 18017 (2018)

11. Smith, I. C. A layered hybrid perovskite solar-cell absorber with enhanced moisture stability. Angew. Chem. Int. Ed. 53, 11414-11417 (2014).

12. Cao, D. H., Stoumpos, C. C., Farha, O. K., Hupp, J. T. \& Kanatzidis, M. G. 2D homologous perovskites as light-absorbing materials for solar cell applications. J. Am. Chem. Soc. 137, 7843-7850 (2015).

13. Tsai, H. et al. High-efficiency two-dimensional ruddlesden-popper perovskite solar cells. Nature 536, 312-317 (2016).

14. Gangadharan, D. T. \& Ma, D. Searching for stability at lower dimensions: current trends and future prospects of layered perovskite solar cells. Energy Environ. Sci. 12, 2860-2889 (2019).

15. Qing, J. et al. High-quality Ruddlesden-Popper perovskite films based on in situ formed organic spacer cations. Adv. Mater. 31, 1904243 (2019).

16. Soe, C. M. M. et al. Understanding film formation morphology and orientation in high member 2D Ruddlesden-Popper perovskites for highefficiency solar cells. Adv. Energy Mater. 8, 1700979 (2018).

17. Chen, Y. et al. Tailoring organic cation of $2 \mathrm{D}$ air-stable organometal halide perovskites for highly efficient planar solar cells. Adv. Energy Mater. 7 1700162 (2017).

18. Zhang, $X$. et al. Orientation regulation of phenylethylammonium cation based 2D perovskite solar cell with efficiency higher than 11\%. Adv. Energy Mater. 8, 1702498 (2018).

19. Lin, Y. et al. Unveiling the operation mechanism of layered perovskite solar cells. Nat. Commun. 10, 1008 (2019).

20. Niu, T. et al. Reduced-dimensional perovskite enabled by organic diamine for efficient photovoltaics. J. Phys. Chem. Lett. 10, 2349-2356 (2019).

21. Li, P. et al. Low-dimensional perovskites with diammonium and monoammonium alternant cations for high-performance photovoltaics. Adv. Mater. 31, 1901966 (2019).

22. $\mathrm{Wu}, \mathrm{G}$. et al. Fine Multi-phase alignments in $2 \mathrm{D}$ perovskite solar cells with efficiency over $17 \%$ via slow post-annealing. Adv. Mater. 31, 1903889 (2019).

23. Zuo, C. et al. Self-assembled $2 \mathrm{D}$ perovskite layers for efficient printable solar cells. Adv. Energy Mater. 9, 1803258 (2019).

24. Vekilov, P. G. Nucleation. Cryst. Growth Des. 10, 5007-5019 (2010).

25. Erdemir, D., Lee, A. Y. \& Myerson, A. S. Nucleation of crystals from solution: classical and two-step models. Acc. Chem. Res. 42, 621-629 (2009).

26. Zhou, Y. et al. Manipulating crystallization of organolead mixed-halide thin films in antisolvent baths for wide-bandgap perovskite solar cells. ACS Appl. Mater. Interfaces 8, 2232-2237 (2016).

27. Ding, B. et al. Material nucleation/growth competition tuning towards highly reproducible planar perovskite solar cells with efficiency exceeding $20 \%$. J. Mater. Chem. A 5, 6840-6848 (2017).

28. Zuo, C. \& Ding, L. An $80.11 \%$ FF record achieved for perovskite solar cells by using the $\mathrm{NH} 4 \mathrm{Cl}$ additive. Nanoscale 6, 9935-9938 (2014).

29. Zuo, C. et al. Advances in perovskite solar cells. Adv. Sci 3, 1500324 (2016).

30. Kosmatos, K. O., Theofylaktos, L., Giannakaki, E., Deligiannis, D. \& Stergiopoulos, T. Methylammonium chloride: a key additive for highly efficient, stable, and up-scalable perovskite solar cells. Energy Environ. Mater. 2, 79-92 (2019).
31. Liu, J., Leng, J., Wu, K., Zhang, J. \& Jin, S. Observation of internal photoinduced electron and hole separation in hybrid 2-dimentional perovskite films. J. Am. Chem. Soc. 2, 1432-1435 (2017).

32. Qing, J. et al. Aligned and graded type-II ruddlesden-popper perovskite films for efficient solar cells. Adv. Energy Mater. 8, 1800185 (2018).

33. Yang, M. et al. Perovskite ink with wide processing window for scalable highefficiency solar cells. Nat. Energy 2, 17038 (2017)

34. Zheng, F. et al. Triggering the passivation effect of potassium doping in mixed-cation mixed-halide perovskite by light illumination. Adv. Energy Mater. 9, 1901016 (2019).

35. Yuan, M. et al. Perovskite energy funnels for efficient light-emitting diodes. Nat. Nanotechnol. 11, 872-877 (2016).

36. Wang, N. et al. Perovskite light-emitting diodes based on solution-processed self-organized multiple quantum wells. Nat. Photonics 10, 699-704 (2016).

37. Yang, X. et al. Efficient green light-emitting diodes based on quasi-twodimensional composition and phase engineered perovskite with surface passivation. Nat. Commun. 9, 570 (2018).

38. Du, K. Z. et al. Two-dimensional lead(II) halide-based hybrid perovskites templated by acene alkylamines: crystal structures, optical properties, and piezoelectricity. Inorg. Chem. 56, 9291-9302 (2017).

39. Oswald, I. W. H., Koegel, A. A. \& Neilson, J. R. General synthesis principles for Ruddlesden-Popper hybrid perovskite halides from a dynamic equilibrium. Chem. Mater. 30, 8606-8614 (2018).

40. Chen, A. Z. et al. Origin of vertical orientation in two-dimensional metal halide perovskites and its effect on photovoltaic performance. Nat. Commun. 9, 1336 (2018).

41. Zuo, C. \& Ding, L. Modified PEDOT layer makes a $1.52 \mathrm{~V} \mathrm{~V}_{\mathrm{oc}}$ for perovskite/ PCBM solar cells. Adv. Energy Mater. 7, 1601193 (2017).

42. Zuo, C., Vak, D., Angmo, D., Ding, L. \& Gao, M. One-step roll-to-roll air processed high efficiency perovskite solar cells. Nano Energy 46, 185-192 (2018).

43. Kirby, N. M. et al. A low-background-intensity focusing small-angle X-ray scattering undulator beamline. J. Appl. Crystallogr. 46, 1670-1680 (2013).

44. Ilavsky, J. Nika: Software for two-dimensional data reduction. J. Appl. Crystallogr. 45, 324-328 (2012).

45. Jiang, Z. GIXSGUI: A MATLAB toolbox for grazing-incidence X-ray scattering data visualization and reduction, and indexing of buried threedimensional periodic nanostructured films. J. Appl. Crystallogr. 48, 917-926 (2015).

46. Momma, K. \& Izumi, F. VESTA 3 for three-dimensional visualization of crystal, volumetric and morphology data. J. Appl. Crystallogr. 44, 1272-1276 (2011).

\section{Acknowledgements}

The authors acknowledge support from the Australian Centre for Advanced Photovoltaics (ACAP) program funded by the Australian Government through the Australian Renewable Energy Agency (ARENA), the Industrial Innovation Program of CSIRO Manufacturing. The authors also acknowledge Dr. Aaron Seeber of CSIRO for XRD measurements. Part of this work was conducted on the SAXS/WAXS beamline at the Australian Synchrotron, part of ANSTO. Funding support (to F.Z. and K.P.G.) from the ARC Centre of Excellence in Exciton Science (CE170100026) is acknowledged.

\section{Author contributions}

M.G. conceived and directed the whole project. C.Z. designed and participated in all experimental sections. A.D.S. performed the photoluminescence measurements. W.L.T. and C.R.M. performed the GIWAXS measurements, with GIWAXS analysis performed by W.L.T. under the supervision of C.R.M., F.Z. and K.P.G. performed the TRPL and TA measurements. H.W. and D.V. performed the stability measurement. D.A. contributed to the experiment discussion. C.Z. wrote the first draft of the paper. M.G., A.S.R.C. and A.D.S. revised the paper. All authors reviewed and commented on the paper.

\section{Competing interests}

The authors declare no competing interests.

\section{Additional information}

Supplementary information is available for this paper at https://doi.org/10.1038/s43246 020-0036-z.

Correspondence and requests for materials should be addressed to M.G.

Reprints and permission information is available at http://www.nature.com/reprints

Publisher's note Springer Nature remains neutral with regard to jurisdictional claims in published maps and institutional affiliations. 
(c) (i) Open Access This article is licensed under a Creative Commons Attribution 4.0 International License, which permits use, sharing, adaptation, distribution and reproduction in any medium or format, as long as you give appropriate credit to the original author(s) and the source, provide a link to the Creative Commons license, and indicate if changes were made. The images or other third party material in this article are included in the article's Creative Commons license, unless indicated otherwise in a credit line to the material. If material is not included in the article's Creative Commons license and your intended use is not permitted by statutory regulation or exceeds the permitted use, you will need to obtain permission directly from the copyright holder. To view a copy of this license, visit http://creativecommons.org/ licenses/by/4.0/.

() Crown 2020 